\title{
TÍTULO DE HONORIS CAUSA
}

Oração proferida, à comunidade acadêmica, em 5 de março de 2007, pelo Prof. Dr. António José Avelãs Nunes, por ocasião do recebimento do Título de Doutor Honoris Causa da Universidade Federal do Paraná, no Salão Nobre da Faculdade de Direito.

Senhor Reitor da Universidade Federal do Paraná, Senhor Decano do Conselho Universitário, Senhores Membros do Conselho Universitário, Senhor Director da Faculdade de Direito da UFPR, Senhor Reitor da Universidade de Coimbra, Caros Colegas, Prezados Estudantes, Meus Amigos.

1 - A minha primeira palavra é, por imperativo de consciência, que não por razões protocolares, para saudar o Reitor da UFPR e, na sua pessoa, homenagear esta Universidade, a mais antiga criada no Brasil, tal como a Universidade de Coimbra é a mais antiga universidade portuguesa, talvez mesmo a mais antiga universidade pública europeia, criada que foi por acto régio de D. Dinis.

Quero dizer-lhe, Senhor Reitor Carlos Moreira Júnior, que é uma honra para mim passar a fazer parte do claustro dos doutores desta Universidade. Muito obrigado por ter acolhido a proposta da Faculdade de Direito e por tê-la apoiado junto do Conselho Universitário.

É tempo, agora, de homenagear a Faculdade de Direito da UFPR, que me habituei a considerar a minha segunda Casa. Faço-o na pessoa do seu Director, Prof. Luiz
Alberto Machado, que esteve, desde o início, entre o pequeno grupo que pôs em marcha a ideia de me ser concedido o título de Doutor Honoris Causa, ideia que defendeu perante o Conselho Universitário, em seu nome e em nome da sua Faculdade.

Devo uma palavra de reconhecimento ao Prof. Rogério Molinari, que foi relator do processo que conduziu à aprovação pelo Conselho Universitário da proposta de concessão do título de Doutor Honoris Causa. Os médicos estão habituados a lidar com casos difíceis e a salvar todos os que recorrem aos seus serviços, os bons e os maus. Perante este caso difícil, o Prof. Molinari empenhouse em salvar a minha causa, apesar dos poucos méritos dela. Aqui lhe deixo o testemunho da minha gratidão.

Uma palavra de agradecimento é devida aos Membros do Conselho Universitário, que decidiram por unanimidade outorgar-me a 
mais alta distinção universitária. A vossa decisão encheu-me de alegria, mas impôs-me um pesado encargo. $\mathrm{O}$ de ser digno da distinção que me foi concedida.

Comovidamente, aqui deixo o meu abraço fraterno a todos os Colegas desta Faculdade de Direito da UFPR, que me acompanharam ao longo do caminho que conduziu à deliberação do Conselho Universitário em razão da qual aqui nos encontramos.

Sem esquecer nenhum dos outros, que daqui saúdo com amizade, recordarei dois deles.

O Prof. Luiz Edson Fachin, por cuja mão visitei pela primeira vez esta Faculdade e a cidade de Curitiba. $\mathrm{O}$ nosso encontro foi um caso de amizade à primeira vista, que se multiplicou numa cadeia de amizades que ultrapassaram esta terra de pinhais e as fronteiras do Paraná, estendendo-se a todo o Brasil.

A Prof. a Aldacy Coutinho, a cuja amizade e generosidade devo a sementeira de ideias e de afectos que frutificou no momento feliz que hoje vivo convosco, neste edifício histórico, símbolo da Universidade e símbolo da Cidade.

A todos os meus Amigos brasileiros (alguns aqui presentes) quero agradecer o privilégio de me aceitarem como seu amigo e a honra de poder contá-los entre os meus melhores Amigos. Não vou dizer os seus nomes. Eles sabem - os presentes e os ausentes - a quem me refiro. E eu sei quanto lhes devo, no plano intelectual e no plano afectivo.

Permita-me, Senhor Reitor Carlos Moreira, uma palavra de sentido reconhecimento ao Reitor da Universidade de Coimbra,
Prof. Eng. Fernando Seabra Santos, que entendeu dever estar pessoalmente presente nesta cerimónia, num gesto que muito me sensibiliza e que diz bem do grau de exigência com que o Doutor Seabra Santos encara o seu múnus reitoral. Sublinhado o gesto do Reitor, direi ao Amigo: apesar dos meus esforços para te dissuadir de fazer a viagem, decidiste vir. Bem hajas pela tua amizade.

Não duvido de que a honra que me é concedida - a maior honra a que um universitário pode aspirar - só circunstancialmente tem que ver com os meus méritos pessoais. Na minha pessoa, quiseram V. Ex ${ }^{\mathrm{a}} \mathrm{s}$ homenagear a Universidade de Coimbra, a Universidade criada em 1290 por um rei-poeta, "plantador de naus".

Mas o simples facto de terem V. Ex ${ }^{a}$ s entendido que eu poderia ser o pretexto para esta homenagem à Universidade de Coimbra é uma distinção que eu só mereço por uma razão: porque $\mathrm{V}$. $\mathrm{Ex}^{\mathrm{a}} \mathrm{s}$ assim o decidiram. Não posso cometer a indelicadeza - que seria, ainda por cima, ingratidão - de pôr em causa a justeza da vossa decisão. Aceito-a com toda a humildade, invocando - e já não é pouca imodéstia da minha parte - o dito de um personagem de Saramago: "conheces o nome que te deram, não conheces o nome que tens". Eu sei apenas o nome que os meus pais me deram, não conheço o nome que tenho, não conheço a ideia que os outros fazem de mim.

Do fundo do coração, agradeço a vossa generosidade para comigo. E fico-me por aqui em matéria de agradecimentos. Porque acredito que, "em assuntos de sentimento, quanto maior for a parte de grandiloquência, menor será a parte de verdade". (José Saramago) 
2 - Se eu fosse Fernando Pessoa/Bernardo Soares, saberia "dar a cada emoção uma personalidade, a cada estado de alma, uma alma”. Mas não sou. Por isso, fiel à cultura camponesa da minha terra, vou tentar contarvos algumas histórias.

Em 1985, coube-me o privilégio de fazer o elogio académico de Tancredo Neves, recémeleito Presidente do Brasil, na cerimónia solene do seu Doutoramento Honoris Causa pela Faculdade de Direito da Universidade de Coimbra. Saudei-o como descendente de portugueses dos Açores que se manteve fiel aos ideais democráticos. Mas nele saudei, jubilosamente, o povo brasileiro que acabara de se libertar da ditadura.

Na parte final da cerimónia, ostentando já o anel, a borla e o capelo de Doutor em Direito, Tancredo Neves tomou o seu lugar nos cadeirais, junto de mim. Com ar cansado, muito comovido, segredou: "Valeu a pena ter chegado até hoje, só para viver este momento".

Perante vós, nesta Sala dos Actos Solenes, é o que me apetece dizer, não em segredo, mas em voz alta.

3 - Chegado aqui, poderia apresentarme como o fez José Saramago no discurso que proferiu ao receber o Prémio Nobel da Literatura, no qual contou histórias dos avós pastores de porcos, com os quais viveu a infância. Também eu poderia falar dos meus avós analfabetos, moleiro um, pastor de cabras o outro. E falar do meu pai alfaiate e da minha mãe costureira. Esta é a minha linhagem. Estas são as minhas raízes, raízes fincadas no povo "que trabalha dia e noite sem esmorecer", no povo que faz a história mas "não cabe nas crónicas" dos historiadores
(Miguel Torga), "gente cujo rosto / Às vezes luminoso / E outras vezes tosco / Ora me lembra escravos / Ora me lembra reis", para utilizar os versos com que uma poetisa portuguesa (Sophia de Mello Breyner) caracteriza o povo português.

Poderia falar-vos dos meus cinco tios que tiveram de emigrar para o Brasil e por cá morreram brasileiros, quase tão pobres como quando chegaram, deixando por cá filhos, netos e bisnetos.

Poderia contar-vos a história do meu próprio pai, que, em meados do século passado, tentou também ele a sua sorte em terras brasileiras, sorte madrasta que o obrigou a regressar a casa, mais pobre e mais sofrido do que quando dela partira.

O sangue brasileiro é, pois, sangue do meu sangue. Este parentesco faz-me feliz e quase me autoriza a considerar-me brasileiro por direito próprio.

4 - Mas esta é uma memória que pouco vos interessa. Talvez valha a pena, porém, recordar aqui uma outra memória, a memória de um "tempo carcerário" (Orlando de Carvalho), um tempo em que a Pátria era "lugar de exílio" (Daniel Filipe), um tempo de raiva, em que os poetas tinham "remorsos da beleza", invectivavam o sol, por "nascer todos os dias / no emprego burocrático de dar razão aos relógios", um tempo em que, mais uma vez nos versos de José Gomes Ferreira, os poetas faziam "versos contra a Paisagem do mundo / - essa prostituta que parece andar à ordem dos ricos para adormecer os pobres".

Nesse tempo salazarento, concluí em 1962 a minha licenciatura em Direito, vivendo de bolsas de estudo desde os quinze 
anos. O meu projecto de então era ser juiz. Barraram-me o caminho por razões políticas. Pouco depois, recusei um lugar de quadro superior num banco por preferir a carreira académica. A polícia política conseguiu adiar o meu contrato até 1967. E só cedeu perante a acção determinada do Director da minha Faculdade, talvez a única Escola portuguesa que, durante aqueles anos de chumbo, fez ponto de honra em não recusar ninguém por razões ideológicas.

Como norma de trabalho, creio poder dizer que segui à risca o conselho de Fernando Pessoa/Ricardo Reis (Odes): "Sê todo em cada coisa. Põe quanto és / No mínimo que fazes". Mas foi o conselho de um grande Mestre da minha geração, o Doutor Orlando de Carvalho, que mais profundamente marcou a minha atitude de universitário: "Faça-se respeitar tal como é. Para isso é preciso pisar os terrenos do adversário", disse-me ele quando entrei na Faculdade como segundo-assistente. E assim procurei fazer, ao longo dos anos.

5 - Com o início da guerra colonial, a opressão agravou-se em Portugal. Em 1969, os estudantes da UC, em protesto contra o regime, contra a guerra e contra a opressão, fizeram greve a exames, com uma adesão superior a 90\%. O governo abanou e o ministro foi substituído. Uns tempos depois, o novo ministro anunciou reformas que sofreram forte contestação dos sectores mais à direita dentro da Universidade. Num relatório apresentado ao Senado universitário o Director da minha Faculdade criticava duramente aquelas reformas e insinuava que as coisas já tinham ido longe demais, que algumas cátedras estavam a ser utilizadas para 'propaganda' de ideias marxistas.

Entendi - creio que correctamente - que a conversa era comigo. E decidi publicar numa das revistas da Faculdade, com a concordância do respectivo Director, um capítulo das minhas lições de Economia Política em que era clara a influência marxista. O texto saiu depois em livro, sob o título "Os sistemas económicos”. Estávamos em meados de 1973. Não me aconteceu nada, a não ser, porventura, algumas anotações mais na minha ficha na polícia política.

6 - Entretanto, com a Revolução dos Cravos (25 de Abril de 1974), chegou o dia em "emergimos da noite e do silêncio" (Sophia), uma longa noite de 48 anos. Estava desde Setembro/1973 em Paris a preparar a minha tese de doutoramento. Fui a Portugal ver a festa. E já não regressei, mobilizado que fui para integrar o $1^{\circ}$ Governo do Portugal liberto do fascismo. Esse foi o meu trabalho, responsável pelo Ensino Superior e Investigação Científica, até Setembro de 1975. Com a queda do último Governo presidido pelo General Vasco Gonçalves, regressei a Coimbra e à Faculdade de Direito. Os tempos conturbados da contra-revolução 'obrigaramme' a dedicar boa parte do meu tempo e das minhas energias a actividades cívicas que foram adiando o meu doutoramento. Afinal, “ a vida é o que fazemos dela”, como escreveu Fernando Pessoa...

Concluída, finalmente, a tese em Julho de 1983, prestei provas em Maio de 1984. Pois bem. Apesar das "portas que Abril abriu" (Ary dos Santos), neste Maio dez anos depois de Abril, corri o risco de ficar reprovado, de novo por razões políticas. 
A minha tese estuda a problemática do desenvolvimento na América Latina, particularmente no Brasil. Pois um dos arguentes (exterior à Universidade de Coimbra) foi a ponto de inventar um autor argentino - que depois confirmei nunca ter existido! - para me acusar da ignorância grave de desconhecer o principal adversário de Raul Prebisch, o grande economista argentino, primeiro Director da CEPAL, cujas ideias analisei na minha tese. Tudo isto para votar a minha reprovação.

$\mathrm{Na}$ tese, defendia, em síntese, que o único desenvolvimento digno desse nome é o "desenvolvimento do povo, pelo povo e para o povo". E concluía perguntando se um tal desenvolvimento poderá ocorrer no quadro do capitalismo. Terminava deste modo as mais de mil páginas da tese, editada no México pelo Fondo de Cultura Económica e recentemente editada no Brasil pela Quartier Latin, com prefácio de Celso Furtado (o último escrito do grande jurista/economista brasileiro, que aqui recordo, carinhosamente, como um dos meus Mestres): "Por nós, defendemos que a via socialista é aquela que permite a mais eficaz mobilização dos recursos disponíveis para a prossecução dos objectivos enunciados, garantindo uma distribuição mais igual de sacrifícios e benefícios. Acreditamos, com Teixeira Ribeiro - Catedrático de Coimbra com quem sempre trabalhei -, que "o socialismo realizado mostra ser uma técnica eficiente de desenvolvimento de países pobres".

Talvez por isso, um outro membro do júri (também exterior à Universidade de Coimbra) votou a minha reprovação alegando na sua declaração de voto que eu era um cientista comprometido, pelo que não tinha lugar na Universidade. Assim mesmo, como quem diz: cá se fazem, cá se pagam.

7 - Obtido, nestas condições, o título de Doutor, o Conselho Científico da minha Faculdade deliberou, por unanimidade, a minha contratação como professor, o que me permitiu continuar na carreira universitária. Por unanimidade viria também a ser aprovado no concurso para professor associado.

Anos mais tarde, quando me apresentei a provas públicas para obter o título de agregado, o professor que tinha querido reprovar-me por eu ser um cientista comprometido, era professor catedrático da minha Faculdade e, segundo as praxes, seria o arguente da lição de síntese que eu teria de apresentar publicamente, nos termos da legislação que regula as provas de agregação. Entendi, por isso, ser meu dever deixar claro que eu era mesmo um cientista comprometido, para ser julgado como tal.

$\mathrm{Na}$ minha lição (que publiquei em livro logo a seguir) defendi a tese de que a Economia Política surgiu como "ciência da burguesia", comprometida com a acção da burguesia revolucionária no sentido de acelerar a desagregação da ordem feudal e de erguer a nova ordem burguesa, do mesmo modo que a teoria económica marxista (enquanto Crítica da Economia Política) se assumiu como "ciência do proletariado", comprometida com a transformação do mundo, empenhada em "dar à classe operária (...) a consciência das condições e da natureza da sua própria acção". (Engels)

Defendi que a ciência económica sempre esteve, desde as origens, comprometida com um determinado projecto de sociedade. Foi assim com os fisiocratas, com Adam Smith 
e com David Ricardo. Foi assim com Karl Marx. Foi assim com Keynes, cuja obra teórica visou, confessadamente, salvar o capitalismo da derrocada que parecia iminente, perante as ondas de choque da Grande Depressão e os horrores do nazifascismo, já por demais notórios.

Aí fiz uma crítica cerrada do paradigma marginalista, dos seus pressupostos ideológicos, da sua pretensa neutralidade científica, da sua concepção de "economia pura", de "ciência físico-matemática”, "com o mesmo grau de certeza que possui a mecânica racional". Procurei mostrar a sua incapacidade para compreender o capitalismo, e critiquei a sua recusa em analisar o poder, as estruturas do poder, as relações de poder. Defendi que o mercado é, como o estado, um produto social, uma instituição política, e não um mecanismo natural.

Para concluir que a ciência económica é uma ciência política, comprometida com valores.

Pois bem. Exprimindo-se por voto secreto (prática estranha na comunidade universitária, que deveria primar pela transparência), o júri deliberou aprovar-me por unanimidade, ou seja, com o voto favorável do professor que votara a minha reprovação no doutoramento por eu ser um "cientista comprometido". O mesmo viria a acontecer no concurso para professor catedrático, pouco tempo depois.

Tinha conseguido aquilo que me propusera: usar plenamente a liberdade de investigar e de ensinar; não abdicar nunca deste direito essencial à função de professor; ocupar o meu lugar na Universidade sem renegar as minhas ideias.

Tinha aprendido o vero alcance da verdade contida nestes versos de Pessoa
(Odes, Ricardo Reis): “A realidade / Sempre é mais ou menos / Do que nós queremos / Só nós somos sempre / Iguais a nós próprios”.

8 - Dito isto, creio ser meu dever dizer aqui que, mesmo nos anos de chumbo do fascismo, a Faculdade de Direito de Coimbra procurou afirmar-se como uma Escola plural, uma Casa de Cultura, uma Casa de Liberdade, uma Casa onde o confronto das ideias e a tensão da polémica não excluíam o respeito recíproco, uma Casa onde se praticava a "liberdade de aprender e de ensinar" que a Constituição do Portugal Democrático a todos veio garantir. A este propósito, deixem-me contar só mais uma pequena história.

Em 1972, as circunstâncias ofereceramme a feliz oportunidade de publicar em livro uma nota minha de crítica ao conteúdo de uma entrevista de Jan Tinbergen (pouco antes galardoado com o Prémio Nobel da Economia), seguida de um artigo de resposta de Tinbergen e um artigo meu, de maior fôlego (objecto de cortes vários da Censura, na revista onde foi originariamente publicado), criticando de novo, na perspectiva do marxismo, as concepções social-democratas defendidas por Jan Tinbergen.

Chamei ao livro "Do capitalismo e do socialismo". Acontece que esse livro foi lido pelo Doutor Antunes Varela, regressado ao seu lugar de Professor da Faculdade de Direito de Coimbra, após vários anos de ministro do governo de Salazar. Era ele o Ministro da Justiça quando fui impedido de me candidatar à magistratura. No entanto, como professor da FDUC e apesar de eu não lhe ter oferecido o livro, o Doutor Antunes Varela escreveu-me uma carta em que, para 
além de outras referências elogiosas, concluía deste modo:"Apesar da ideologia colectivista que o perpassa de princípio ao fim, este livro honra o seu autor e a Escola que o formou".

Trago-vos esta história, não para me elogiar, mas para homenagear a minha Faculdade, que gosto de recordar assim: plural, tolerante, aberta ao diálogo. É por isso que gosto dela. É por isso que gosto também da minha nova Casa: a Faculdade de Direito da UFPR.

9 - Vivemos um tempo de grande esperança e de grande desespero.

Um tempo de grande desespero. Porque sabemos - lembrou-o a FAO há pouco - que cerca de 18 mil crianças morrem de fome todos dias; que 850 milhões de pessoas deitam-se diariamente sem nada no estômago; que o número de pessoas com fome aumenta ao ritmo de cinco milhões por ano.

$\mathrm{E}$, no entanto, todos sabemos que a humanidade dispõe hoje de recursos para evitar este escândalo intolerável. Pesa sobre nós, universitários-cidadãos, pesa sobre a Universidade-cidadã uma enorme responsabilidade. Digo-o com a força dos versos de uma grande senhora da poesia portuguesa (Sophia de Mello Breyner): "Vemos, ouvimos e lemos. / Não podemos ignorar".

Um tempo de grande esperança também. Porque a revolução científica e tecnológica tem proporcionado fabulosos ganhos de produtividade, que parecem tornar mais real a utopia dos clássicos do marxismo ao assumirem que, um dia, a humanidade há-de passar do reino da necessidade para o reino da liberdade. Sei bem - sabemos todos - que esse dia não será amanhã. Mas talvez tenhamos razões para acreditar que estamos a fazer o caminho. Porque o caminho do futuro do Homem passa pela educação, pelo progresso científico, pela democratização do conhecimento e não pela contra-revolução monetarista e neo-liberal que inspira a política de globalização, que muitos procuram identificar com a revolução científica e tecnológica.

Cabe-nos a nós, universitários, trabalhar para fazer luz nesta noite do "pensamento único" e do "fascismo de mercado" (Paul Samuelson). E não podemos esperar muito mais. Porque, dizendo-o com versos de Xico Buarque, "quem espera nunca alcança".

10 - Termino com um haikai de Helena Kolody:

\section{"Sou voz mínima / cantando / no coral do mundo".}

Bem hajam todos por terem querido encontrar um lugar para mim no vosso coral. Bem hajam todos por me terem ouvido. Perdoem-me pelo tempo que lhes roubei.

Curitiba, 5 de Março de 2007 